\title{
Structure of Carbonic Layer in Ohmic Contacts: Comparison of Silicon Carbide/Carbon and Carbon/Silicide Interfaces
}

\author{
Pawel Borowicz, ${ }^{1,2}$ Adrian Kuchuk, ${ }^{3}$ Zbigniew Adamus, ${ }^{4}$ Michał Borysiewicz, ${ }^{5}$ \\ Marek Ekielski, ${ }^{5}$ Eliana Kamińska, ${ }^{5}$ Anna Piotrowska, ${ }^{5}$ and Mariusz Latek ${ }^{1}$ \\ ${ }^{1}$ Department of Characterisation of Nanoelectronic Structures, Institute of Electron Technology, Al. Lotników 32/46, \\ 02-668 Warsaw, Poland \\ ${ }^{2}$ Department of Photochemistry and Spectroscopy, Institute of Physical Chemistry, Polish Academy of Sciences, \\ Kasprzaka 44/52, 01-224 Warsaw, Poland \\ ${ }^{3}$ Diagnostic Center, V. Lashkaryov Institute of Semiconductor Physics, NAS of Ukraine, Pr. Nauky 45, 03028 Kiev, Ukraine \\ ${ }^{4}$ Laboratory of Growth and Physics of Low Dimensional Crystals, Institute of Physics, Polish Academy of Sciences, \\ Al. Lotników 32/46, 02-668 Warsaw, Poland \\ ${ }^{5}$ Department of Micro- and Nanotechnology of Wide Bandgap Semiconductors, Institute of Electron Technology, \\ Al. Lotników 32/46, 02-668 Warsaw, Poland
}

Correspondence should be addressed to Paweł Borowicz; borowicz@ite.waw.pl

Received 28 October 2012; Accepted 3 December 2012

Academic Editors: J. G. Han and S. Yang

Copyright (C) 2013 Paweł Borowicz et al. This is an open access article distributed under the Creative Commons Attribution License, which permits unrestricted use, distribution, and reproduction in any medium, provided the original work is properly cited.

\begin{abstract}
The structure of carbonic layer in three samples composed of $4 \mathrm{H}$ polytype of silicon carbide and the following sequence of layers: carbon/nickel/silicon/nickel/silicon was investigated with Raman spectroscopy. Different thermal treatment of the samples led to differences in the structure of carbonic layer. Raman measurements were performed with visible excitation focused on two interfaces: silicon carbide/carbon and carbon/silicide. The results showed differences in the structure across carbon film although its thickness corresponds to $8 / 10$ graphene layers.
\end{abstract}

\section{Introduction}

Silicon carbide $(\mathrm{SiC})$ is known as an excellent material for fabrication high-power, high-frequency, and high-temperature electronic devices due to its properties like: good thermal conductivity, high critical electric field, and simple method of dielectric layer fabrication $[1,2]$. Formation of ohmic contacts with low specific resistance is an important aspect in application of silicon carbide [3]. This fabrication is realized by deposition of metallic layer on the substrate surface followed by thermal treatment at high temperature $[4,5]$. Nickel is probably the most popular metal used in technology of ohmic contact formation, because the contacts formed with its application have specific contact resistance equal to $\sim 10^{-6} \Omega \mathrm{cm}^{2}$ [4]. The interaction of carbonic structures with the $\mathrm{SiC}$ substrate was investigated with $\mathrm{X}$-ray photoelectron spectroscopy and Raman scattering [6]. The properties of the ohmic contact are determined by concentration of graphitic nanoflakes formed during the annealing procedure. The initial structure of carbon film has no impact on properties of the formed contact $[6,7]$. In previous work, structural and electrical properties of different $\mathrm{Ni}$ - and $\mathrm{Ni} / \mathrm{Si}$-based contacts to silicon carbide were investigated [8]. Reported structural data obtained by various experimental techniques like X-ray diffraction (XRD), Rutherford Backscattering Spectrometry (RBS), and Secondary Ion Mass Spectrometry (SIMS) showed that optimal metallization sequence for manufacturing ohmic contacts is $\mathrm{Ni} / \mathrm{Si} / \mathrm{Ni} / \mathrm{Si}$. The thicknesses of each layer should provide optimal conditions for creation of $\mathrm{Ni}_{2} \mathrm{Si}$ silicides.

This paper focuses the attention on structural properties on different sides of thin carbon film introduced between $\mathrm{SiC}$ substrate and nickel/silicon/nickel/silicon sequence of layer. Since thermal treatment at high temperature results in $\mathrm{SiC}$ decomposition, new carbon atoms appear at the interface between silicon carbide substrate and deposited carbonic layer. Decomposition of silicon carbide leads up to creation 
of carbon structures with preferred $\mathrm{ABC}$ stocking order [9]. Annealing above $800^{\circ} \mathrm{C}$ results in structural changes in carbon structure and migration of carbon atoms towards free silicide surface.

The main topic discussed in this work is the comparison of the structure observed for carbon layer at different sides: $\mathrm{SiC} / \mathrm{C}$ interface and $\mathrm{C} / \mathrm{Ni}_{2} \mathrm{Si}$ interface. As an experimental technique, Raman spectroscopy was chosen. Due to large penetration depth of visible light into silicide layer and silicon carbide substrate, it was possible to observe Raman spectra excited from both sides of carbon film introduced between $\mathrm{Ni} / \mathrm{Si} / \mathrm{Ni} / \mathrm{Si}$ sequence and $\mathrm{SiC}$ substrate.

\section{Experimental}

2.1. Samples. The preparation of the samples was already described in the paper concerning visible and ultraviolet Raman study of carbon properties in ohmic contacts [10].

The samples will be called hereafter $n s c 1$ 2 (temperature of the second annealing step $800^{\circ} \mathrm{C}$ ), nscl_3 (temperature of the second annealing step $950^{\circ} \mathrm{C}$ ), and $n s c 1 \_1$ (temperature of the second annealing step $1000^{\circ} \mathrm{C}$ ).

2.2. Apparatus and Experimental Conditions. Raman scattering was measured with MonoVista 2750i micro-Raman confocal spectrometer (Spectroscopy and Imaging $\mathrm{GmbH}$, Germany). The microscopic part was based on Olympus BX51 microscope. The images from microscope were recorded with TM 2040GE imaging camera (JAI, Japan). Motorized stage (Märzhauser $\mathrm{GmbH}$, Germany) allowed sample positioning with accuracy equal to $100 \mathrm{~nm}$ in $x, y$, and $z$ directions. The positioning mechanism worked in feedback loop in order to stabilize the position of the stage. Spectral part of the MonoVista was based on Princeton Instruments spectral devices: spectrograph SpectraPro 2750i (focal length $750 \mathrm{~mm}$ ) and spectral nitrogen-cooled CCD camera LN/2048 × 512B/I UVAR, Spec-10 System with maximum efficiency at $250 \mathrm{~nm}$.

As an excitation light, the $\mathrm{Ar}^{+}$laser INNOVA 90C (Coherent, USA) line $(\lambda=488 \mathrm{~nm})$ was used. The power of laser light on the sample was below $1 \mathrm{~mW}$ in order to avoid thermal effects caused by focused laser light. The grating with 1800 lines $/ \mathrm{mm}$ and blazed for visible spectral range was used to measure Raman spectra. Two types of excitations were used: through the silicide layer, hereafter called also top excitation, and through $\mathrm{SiC}$ substrate, hereafter called also bottom excitation. Although confocal configuration strongly reduced signal generated outside the focal plane bottom, excitation introduces strong component of two-phonon scattering from $4 \mathrm{H}-\mathrm{SiC}$. Huge difference between thickness of $\mathrm{SiC}$ substrate and carbon film $(\sim 1 \mathrm{~mm}$ versus $3 \mathrm{~nm})$ caused large signal from $4 \mathrm{H}$-SiC substrate placed outside focal plane. In order to separate Raman scattering generated by carbon layer from two-phonon $\mathrm{SiC}$ background, two measurements were necessary to get "pure" spectrum of carbon layer. The first measurement was taken from the area covered with carbon layer and the second one outside of this area. The "pure" carbon spectrum was calculated by subtraction of twophonon $\mathrm{SiC}$ spectrum measured outside of the covered area from the spectrum collected from area covered with carbon and silicide layers. In order to obtain good signal-to-noise ratio, long irradiation time, about 1 hour, was applied for measurement of single spectrum.

2.3. Spectra Analysis. The spectra were mathematically processed before analysis and interpretation. Mathematical treatment included offset removal, baseline correction, smoothing, and normalization. Measured spectra were normalized to unity. The procedure used to calculate pure carbon spectra from bottom excitation measurements was similar to the procedure used in the study of carbon inclusions at $\mathrm{SiC} / \mathrm{SiO}_{2}$ interface [11].

\section{Results}

Raman spectra measured with visible excitation $\left(\lambda_{\text {exc. }}=\right.$ $488 \mathrm{~nm}$ ) and irradiation through the silicide layer are presented in:

$$
\begin{aligned}
& \text { Figure } 1(\mathrm{a}) \text { - data obtained for } n s c 1 \_2 \text {, } \\
& \text { Figure } 1(\mathrm{~b}) \text { - for } n s c 1 \_3, \\
& \text { Figure } 1(\mathrm{c})-n s c 1 \_1 .
\end{aligned}
$$

The main plot of each panel shows the experimental data together with fitted Gaussian profiles. The upper inset in each panel compares experimental points with fitted function (the sum of Gaussian profiles used to reconstruct the experimental data). The lower inset presents autocorrelation function which attests to quality of fitting procedure. The maxima of Gaussian profiles fitted to experimental data are given in the main plot of each panel. Random distribution of points around zero level in autocorrelation function bears testimony to the quality of fitting procedure. Qualitative description of the spectra measured for top excitation was already presented in the paper comparing visible and deep-ultraviolet Raman investigation of these samples, and it will be not repeated here in details [10]. The main difference between the results presented here and in [10] is the number of profiles necessary for reconstruction $D$ and $G$ bands in the case of samples $n s c 1 \_3$ and $n s c 1$ 1. In [10], one Lorentzian component was sufficient to reconstruct each band, whereas, here, two Gaussian profiles are necessary. The detailed description of the results obtained from mathematical analysis performed in this work will be reported in the part Discussion.

Subtracted spectra obtained from bottom excitation are presented in Figure 2. The data in Figure 2 are presented in the same way as in Figure 1. It means that the main plot of each panel shows experimental points and Gaussian profiles used in fitted function, upper inset compares the whole fitted function with experimental data, and lower inset presents the autocorrelation function. The maxima of Gaussian profiles are given in the main plot of each panel. In the case of each sample, different numbers of Gaussian profiles are necessary to reconstruct the course of experimental points. Four profiles are necessary to reproduce the shape of the subtracted spectrum in the case of $n s c 1 \_2$, for $n s c 1 \_3$, as many as seven profiles are necessary and for $n s c 1,1$, six. The detailed discussion of the mathematical analysis will be presented in next the part of this paper. In this chapter, the description of 


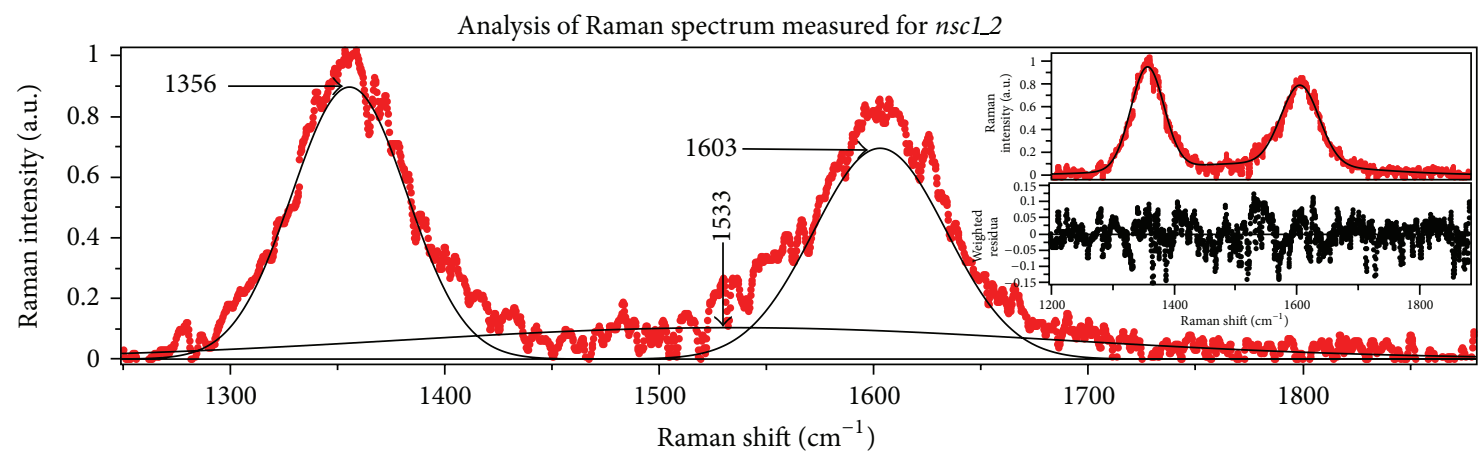

(a)

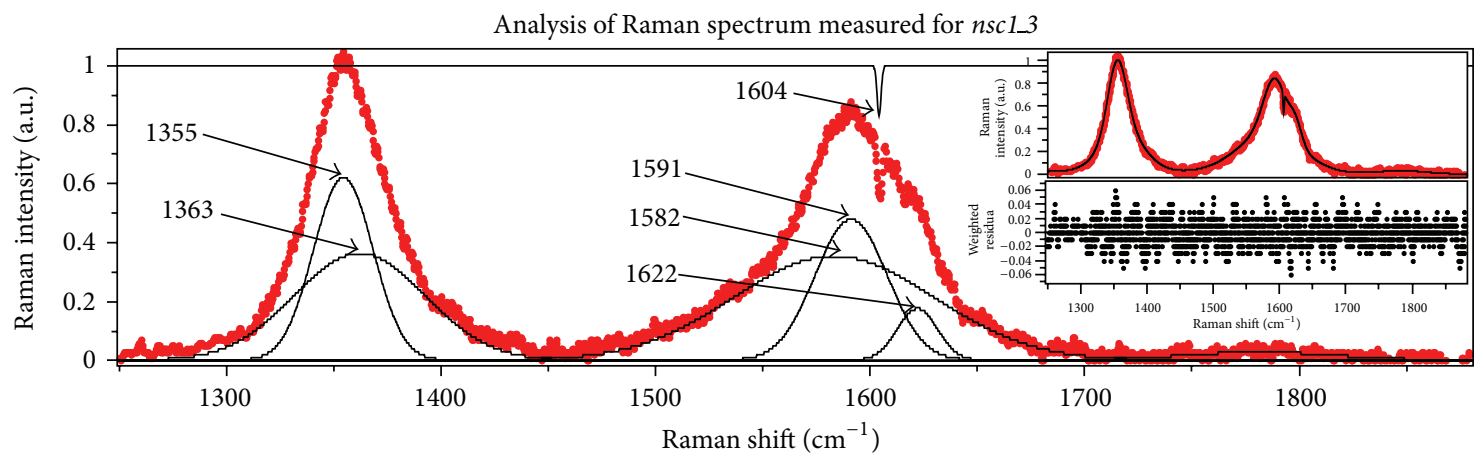

(b)

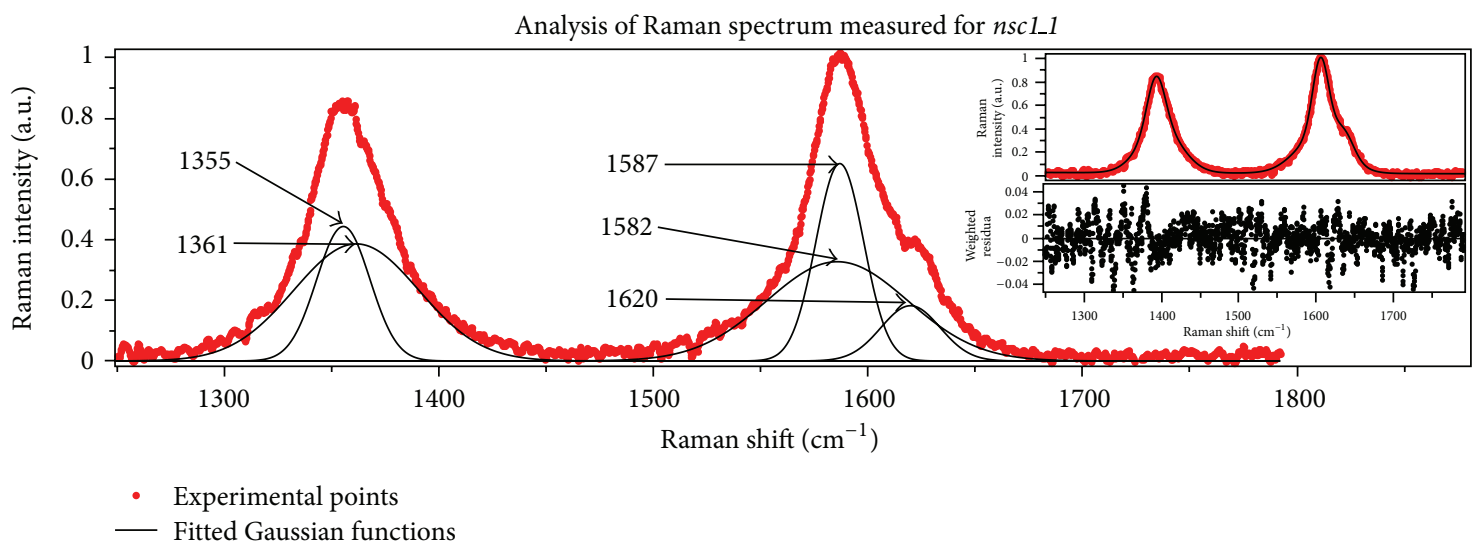

(c)

FiguRE 1: Analysis of Raman spectra measured for different samples with excitation through silicide layer $\left(\lambda_{\text {exc. }}=488 \mathrm{~nm}\right)$. (a) presents the data obtained for $n s c 12$, (b) for $n s c 1 \_3$, and (c) for $n s c 1$. The main plot in each panel shows experimental points together with fitted Gaussian profiles. The maxima positions are given in the plot. Upper inset compares experimental points with fitted function, and the lower inset shows the quality of fitting procedure by means of autocorrelation function.

the spectra is limited to qualitative discussion of its main features. Two strong bands are present in the spectrum of each sample. The maximum of the first one is placed between about $1520 \mathrm{~cm}^{-1}$ and about $1540 \mathrm{~cm}^{-1}$. The maximum of the second band appears between $1580 \mathrm{~cm}^{-1}$ and $1610 \mathrm{~cm}^{-1}$. Maximum position of the first band is correlated with amorphous carbon $(a-C)[12,13]$. The position of the second observed band is typical for $G$ band reported for different types of graphite.
Maximum placed slightly above $1600 \mathrm{~cm}^{-1}$ and obtained here for $n s c 1 \_2$ and $n s c 1 \_3$ subtracted spectra is a typical trace of nanocrystalline graphite $[12,13]$. The maximum shifted to lower values of Raman shift and placed between $1580 \mathrm{~cm}^{-1}$ and $1590 \mathrm{~cm}^{-1}$ in the case of $n s c 1$ is reported in the literature for graphite in crystalline form $[12,13]$. To sum up, for the first look, Raman spectra of carbon layer observed from the side of silicon carbide substrate can be assigned 


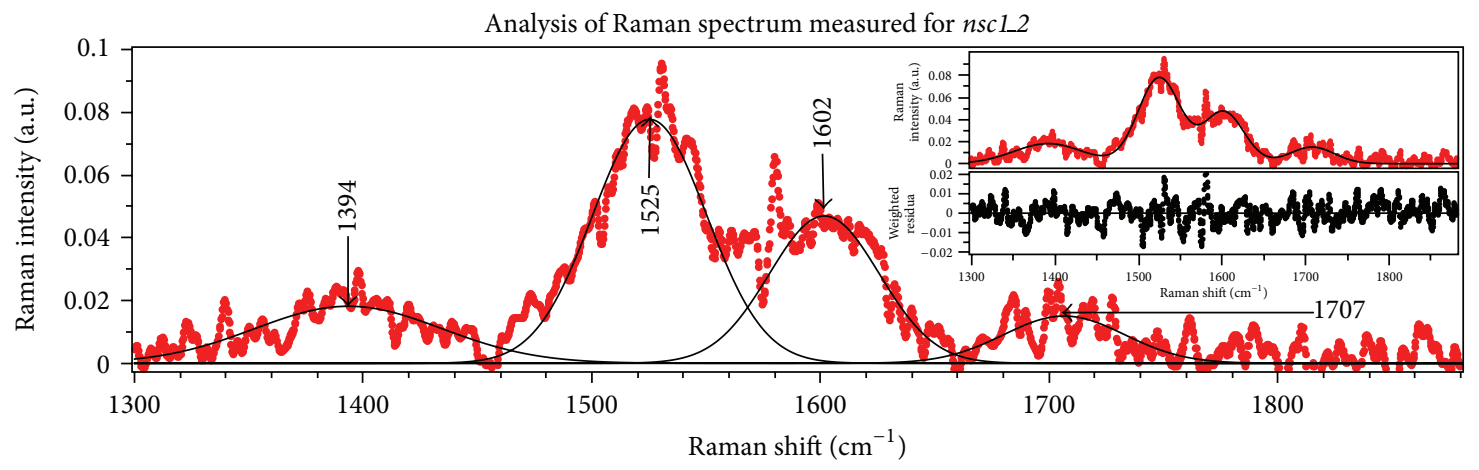

(a)

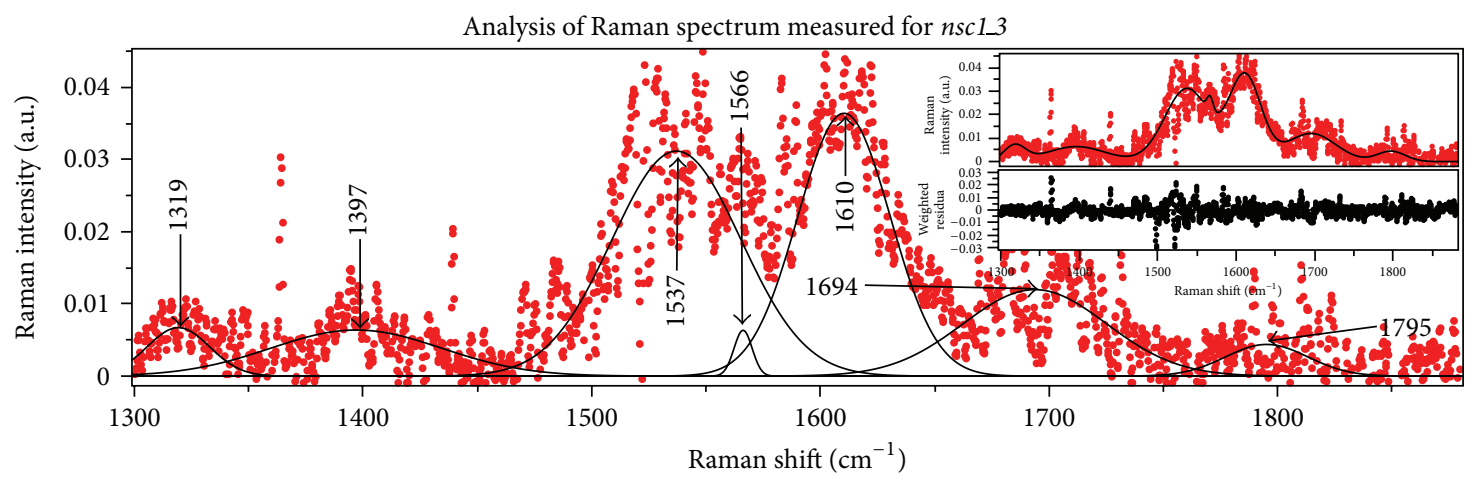

(b)

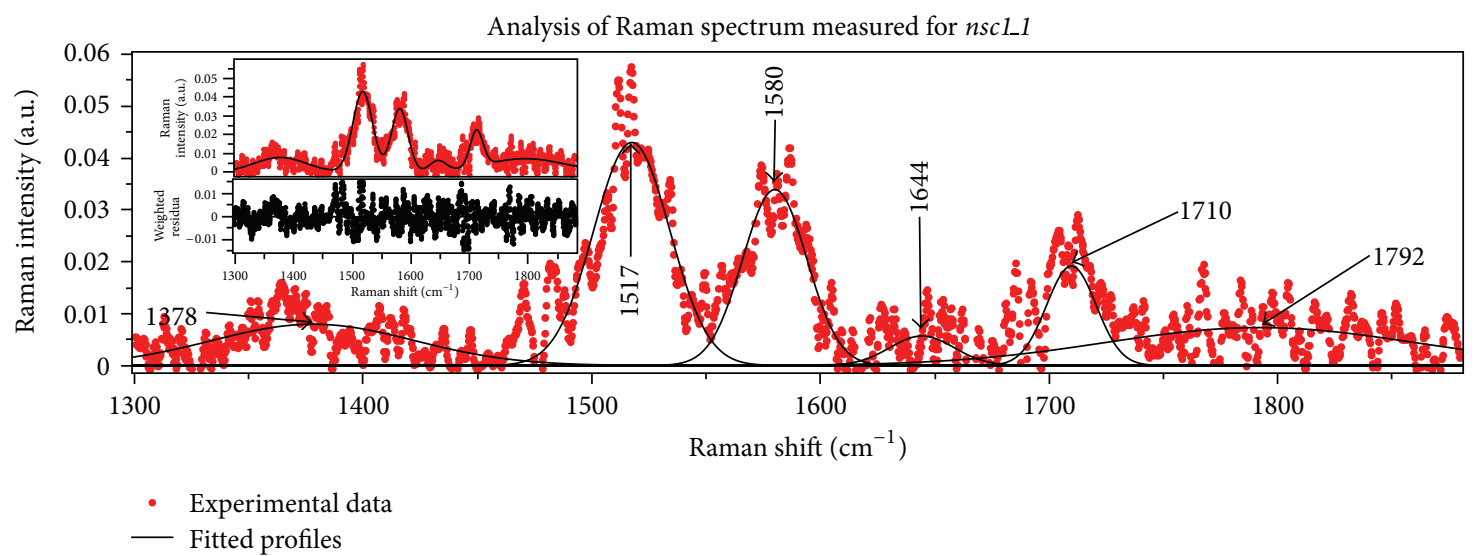

(c)

FiguRE 2: Analysis of subtracted Raman spectra obtained from visible excitation through the silicon carbide substrate. (a) presents the data obtained for $n s c 1 \_2$, (b) for $n s c 1 \_3$, and (c) for $n s c 1 \_1$. The convention used in Figure 2 is the same as in the case of Figure 1.

to the mixture of $a$ - $\mathrm{C}$ with different forms of graphite. The type of graphite component seems to be dependent on the temperature applied in the second step of thermal treatment.

The spectra measured for $2 D$ band are presented in Figure 3(a) showing data obtained for $n s c 1$ 3, Figure 3(b) and for $n s c 11$. In the case of $n s c 1 \_2$ sample, the signal in this range of Raman shift was too small to distinguish unequivocally $2 D$ band [10]. The convention used in Figure 3 is the same as in Figures 1 and 2. The main plot of each panel presents experimental points together with fitted Gaussian profiles.
The maxima of the profiles are given in the plot. Upper inset compares experimental points with fitted function, and lower inset presents autocorrelation function as a certificate of fitting quality. The qualitative description of the spectra was presented earlier [10], and it will be not repeated here in detail. Briefly, $2 D$ band observed for $n s c 1 \_3$ has slightly larger FWHM than the band recorded for nscl_l. The band observed for $n s c 11$ has the red side slightly shifted towards higher frequencies. The detailed discussion of mathematical analysis will be presented in the next part. 


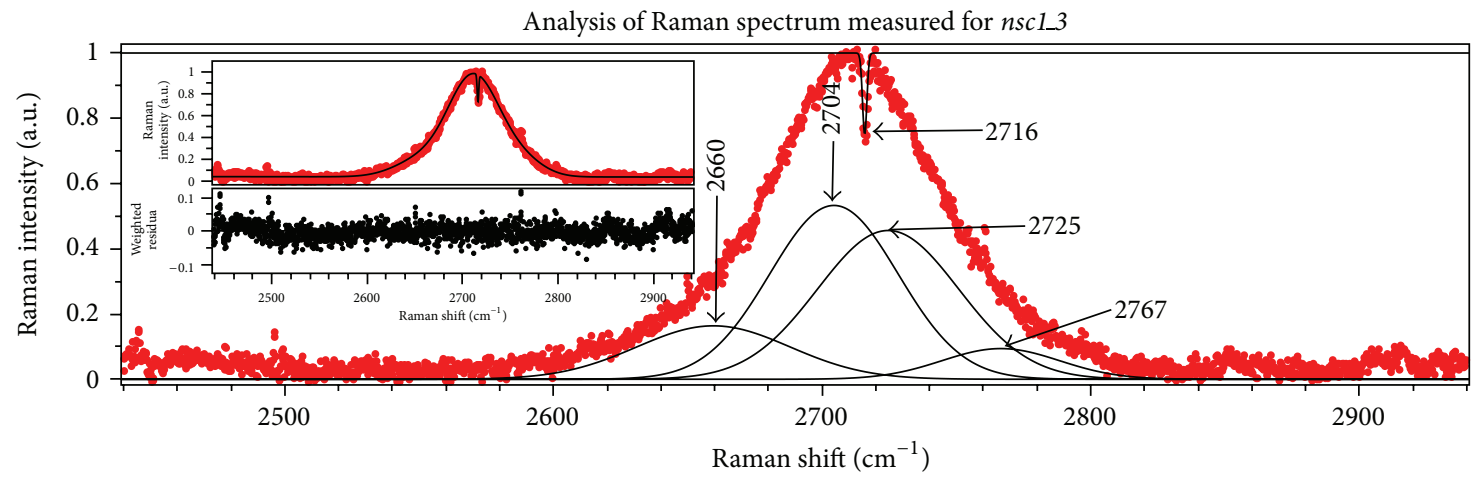

(a)

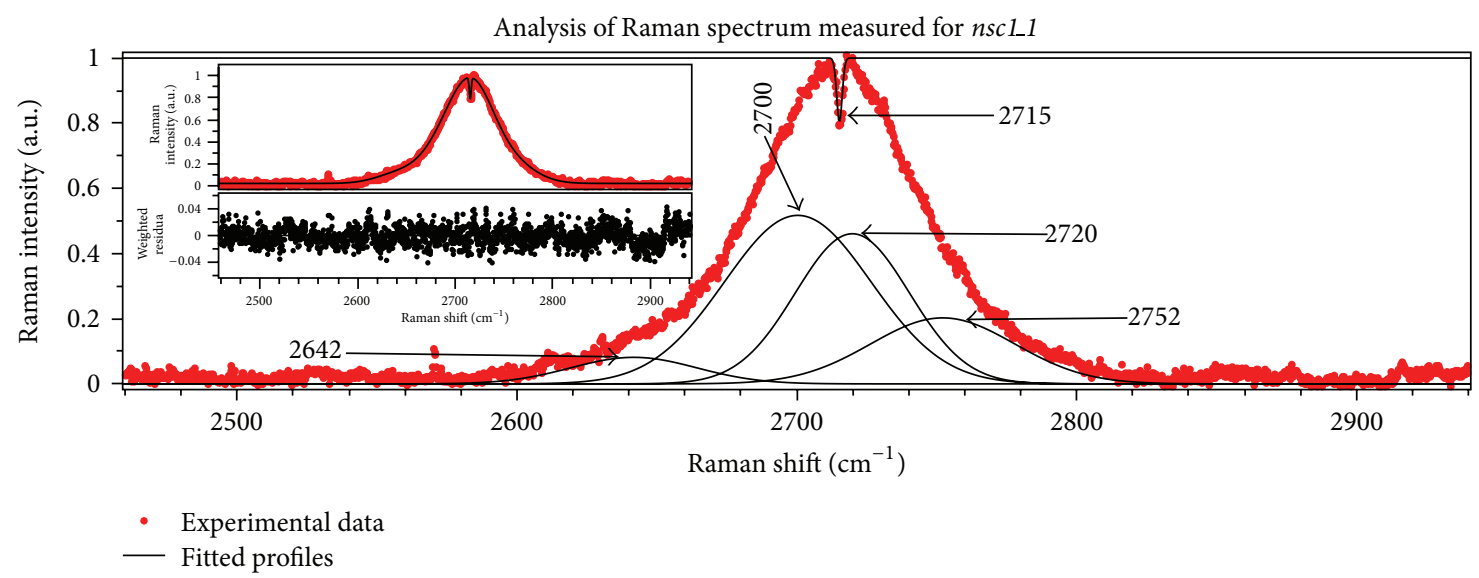

(b)

Figure 3: Analysis of $2 D$ band measured with top excitation for $n s c 1 \_3$ (a) and $n s c 1 \_1$ (b). No unequivocal signal that can be assigned to $2 D$ band was observed in this range of Raman shift for $n s c 1 \_$. The convention used in Figure 3 is the same as in Figures 1 and 2.

\section{Discussion}

The list of Raman bands found with application of mathematical analysis in spectra excited through the silicide layer is presented in Table 1. Each band is characterized by maximum position, half width FWHM, and relative intensity. The last column of the table contains proposed assignment of the band. The carbon layer in samples from $n s c 1_{-} n(n=$ $1,2,3)$ series has no uniform, ideal crystal structure but is composed of graphite domains. In such a case, measured Raman spectra contain the information about structures with crystallographic parameters scattered around the main values. Reliable information about the intensity of the main crystalline structure is derived from the height of the fitted profile and not from the area under the curve [12]. Because of this, the intensities given in this work are determined from the heights of fitted Gaussian functions. In the case of each sample presented in Table 1, intensities are normalized to the height of the profile reproducing $G$ band. For samples nscl_1 and $n s c 133$, for which two Gaussian functions are necessary for reconstruction of $G$ band, the profile with smaller FWHM is taken as reference.
Three Gaussian components are necessary for reconstruction of Raman spectrum measured for $n s c 12$. The first and third ones reproduce $D$ and $G$ bands. Their maxima positions and FWHMs are close to those which were reported for the model based on Lorentzian functions [10]. The maxima positions and FWHM values are typical for nanocrystalline graphite. The intensity ratio $I(D) / I(G)$ is here slightly larger in comparison to the value reported for Lorentzian-based model [10]. In particular, the values of $I(D) / I(G)$ intensity ratio presented here and in [10] are equal to 1.29 and 1.16, respectively. The second Gaussian component of fitted function has the maximum at $1533 \mathrm{~cm}^{-1}$, large FWHM equal to about $360 \mathrm{~cm}^{-1}$, and the intensity much lower than $G$ band (0.16). The maximum of this component corresponds with the data reported for $a-C$. Also, the large value of FWHM is typical for this kind of carbon structure [13]. For example, fused $D$ and $G$ bands observed for carbon films deposited by supersonic cluster beam spread form about $1000 \mathrm{~cm}^{-1}$ to about $1650 \mathrm{~cm}^{-1}$ [14].

The reconstruction of $D$ band observed for samples $n s c 1 \_3$ and $n s c 1 \_1$ requires two Gaussian functions for each sample. In the case of each sample, the pair of Gaussian 
TABLE 1: Summary of results obtained in the case of top excitation. The range of Raman shift spreads from about $1300 \mathrm{~cm}^{-1}$ to about $1880 \mathrm{~cm}^{-1}$. It corresponds to the position of $D$ and $G$ bands.

\begin{tabular}{|c|c|c|c|c|c|c|c|c|c|}
\hline & $n s c 12$ & & & $n s c 1 \_3$ & & & $n s c 1 \_1$ & & \\
\hline $\begin{array}{l}\text { Max. } \\
\left(\mathrm{cm}^{-1}\right)\end{array}$ & $\begin{array}{c}\text { FWHM } \\
\left(\mathrm{cm}^{-1}\right)\end{array}$ & $\begin{array}{l}\text { Norm. } \\
\text { Int. }\end{array}$ & $\begin{array}{l}\text { Max. } \\
\left(\mathrm{cm}^{-1}\right)\end{array}$ & $\begin{array}{c}\text { FWHM } \\
\left(\mathrm{cm}^{-1}\right)\end{array}$ & $\begin{array}{l}\text { Norm. } \\
\text { Int. }\end{array}$ & $\begin{array}{l}\text { Max. } \\
\left(\mathrm{cm}^{-1}\right)\end{array}$ & $\begin{array}{c}\text { FWHM } \\
\left(\mathrm{cm}^{-1}\right)\end{array}$ & $\begin{array}{l}\text { Norm. } \\
\text { Int. }\end{array}$ & Proposed assignment \\
\hline \multirow{2}{*}{1355.3} & \multirow{2}{*}{63.2} & \multirow{2}{*}{1.29} & 1354.5 & 33.4 & 1.31 & 1355.4 & 29.3 & 0.68 & $D$ band \\
\hline & & & 1362.7 & 76.1 & 0.69 & 1361.4 & 68.4 & 0.59 & $D$ band \\
\hline \multirow[t]{2}{*}{1533.3} & 359.9 & 0.16 & - & - & - & - & - & - & $a-\mathrm{C}$ \\
\hline & & & 1581.9 & 113.2 & 0.70 & 1585.7 & 77.5 & 0.50 & $G$ band \\
\hline \multirow[t]{2}{*}{1602.9} & 72.9 & 1.00 & 1591.2 & 40.3 & 1.00 & 1586.8 & 26.2 & 1.00 & $G$ band \\
\hline & & & 1622.2 & 22.8 & 0.36 & 1619.8 & 32.4 & 0.28 & $\begin{array}{l}\text { Combination of } \mathrm{C}=\mathrm{C} \\
\text { and NiGIC vibrations }\end{array}$ \\
\hline- & - & - & 1784.0 & 89.7 & 0.06 & - & - & - & $\begin{array}{l}2 o T O \text { mode or } \\
\text { benzene-related } \\
\text { vibrations }\end{array}$ \\
\hline
\end{tabular}

functions has similar properties. One component has the maximum placed at about $1355 \mathrm{~cm}^{-1}$ and $\mathrm{FWHM}$ equal to about $30 \mathrm{~cm}^{-1}$. The relative intensity of this component decreases about two times from $n s c 1 \_3$ to $n s c 1 \_1$; in particular, it is equal to 1.29 and 0.68 for $n s c 1 \_3$ and $n s c 1 \_1$, respectively. The decrease of normalized intensity between $n s c 1 \_3$ and $n s c 1$ 1 shows the increase of graphitization degree between the samples. The other type of Gaussian function has the maxima shifted towards larger values of Raman shift. The positions are equal to about $1363 \mathrm{~cm}^{-1}$ and $1361 \mathrm{~cm}^{-1}$ for $n s c 1 \_3$ and $n s c 1 \_1$, respectively. The FWHM values obtained for this type of Gaussian functions are about twice larger than the corresponding parameters obtained for previously described "narrow" profiles. The values are equal to about $76 \mathrm{~cm}^{-1}$ and $68 \mathrm{~cm}^{-1}$ for $n s c 1 \_3$ and $n s c 1 \_1$, respectively. The normalized intensities are in the case of these "broad" profiles similar and they are equal to 0.69 and 0.59 for $n s c 1 \_3$ and $n s c 1$, 1 , respectively. The requirement to use two Gaussian function for $D$ band reconstruction can be associated with difference in the structure of carbon layer along its thickness. Comparison of Figures 1 and 2 shows differences in crystalline structure of carbon layer observed for top and for bottom excitations. It means that the crystalline structure of the layer should change across this layer. The "narrow" Gaussian component in Raman spectra recorded for samples $n s c 1 \_3$ and nsc1_1 describes this part of the layer which has regular graphite structure. The "broad" profile corresponds to structures which have the crystalline parameters scattered around the mean values. This distribution of crystalline parameters is reflected in relatively large FWHM equal to about $70 \mathrm{~cm}^{-1}$. The hypothesis that "broad" Gaussian function in $D$ band reproduces this part of Raman spectrum which is generated by structures with scattered structural parameters is supported by the reconstruction of $G$ band. In the case of samples $n s c 1 \_3$ and $n s c 1 \_1$, three Gaussian functions are necessary for proper reconstruction of $G$ band. The third profile has the maximum at about $1622 \mathrm{~cm}^{-1}$ and $1620 \mathrm{~cm}^{-1}$ for $n s c 1 \_3$ and $n s c 11$, respectively. The FWHM values of this band are equal to about $23 \mathrm{~cm}^{-1}$ and $32 \mathrm{~cm}^{-1}$ for $n s c 1 \_3$ and $n s c 1 \_1$, respectively. Normalized intensities of these Gaussian functions are equal to 0.36 and 0.28 for $n s c 1 \_3$ and $n s c 11$, respectively. This band originates mainly from structure with double $\mathrm{C}=\mathrm{C}$ bonds in the case of $n s c 1 \_3$ and from nickel-graphite intercalated compounds (NiGICs) in the case of $n s c 11$. Details of this assignment were already discussed [10]. Two remaining Gaussian functions form the pair consisting of "narrow" and "broad" components similar to the pair of functions reconstructing $D$ band. The "narrow" components have the maxima placed at about $1591 \mathrm{~cm}^{-1}$ and $1587 \mathrm{~cm}^{-1}$ for $n s c 13$ and $n s c 1$, respectively. The corresponding values of FWHM are equal to about $40 \mathrm{~cm}^{-1}$ and $26 \mathrm{~cm}^{-1}$. The "broad" Gaussian components have the maxima placed at about $1582 \mathrm{~cm}^{-1}$ and $1586 \mathrm{~cm}^{-1}$, and corresponding FWHM values are equal to about $113 \mathrm{~cm}^{-1}$ and $78 \mathrm{~cm}^{-1}$ for $n s c 1 \_3$ and $n s c 1 \_1$, respectively. The normalized intensities of "broad" components are equal to 0.70 and 0.50 for $n s c 1 \_3$ and $n s c 1 \_1$, respectively. The FWHM observed in the case of both components ("narrow" and "broad") is smaller for $n s c 1 \_1$ in comparison with nsc1_3. This decrease suggests larger homogeneity of carbon layer in the case of $n s c 1 \_$. Both components can be interpreted as $G$ band in particular,

(i) "narrow" component can be associated with regular graphite structure;

(ii) "broad" component is generated by structures with crystallographic parameters scattered around mean values.

The maxima positions obtained for "narrow" components have larger values in comparison with maxima of "broad" structures contributing to $G$ band. The maximum of $G$ band reported for ABA stacking order is shifted towards larger frequencies in comparison with the maximum of this band in the case of ABC stacking order [15]. One can expect the dominance of ABA stacking order in "narrow" component and $\mathrm{ABC}$ stacking order in "broad" one [10]. The carbon layer with $\mathrm{ABC}$ stacking order appears in the vicinity of $\mathrm{SiC} / \mathrm{C}$ interface due to interaction between silicon carbide substrate and carbon layer [9]. Therefore, the structures contributing to the "broad" components of $D$ and $G$ bands should be placed 
near $\mathrm{SiC}$ substrate, and "narrow" components of $D$ and $G$ bands should be generated in the part of carbon layer placed in the vicinity of silicide layer.

The last band given in Table 1 has the maximum at about $1784 \mathrm{~cm}^{-1}$, FWHM equal to about $90 \mathrm{~cm}^{-1}$, and very weak intensity equal to about $6 \%$ of the intensity obtained for the "narrow" component of $G$ band. It was found in the spectrum of $n s c 1 \_3$ only. The band is placed in the range of Raman shift where out-of-plane vibrational modes of graphite are reported in the literature [16]. In particular, the best correlation of the maximum band is with the position of so-called $M$ band [17]. This $M$ band was assigned to the overtone of out-of-plane Transverse Optical (2oTO) mode [18]. The other reported in the literature, carbon band placed in the vicinity of $1784 \mathrm{~cm}^{-1}$, is assigned to benzene-related vibrations $[19,20]$. It has the maximum at about $1740 \mathrm{~cm}^{-1}$. The correlation of the band centred around $1784 \mathrm{~cm}^{-1}$ with the combination of in-plane Transverse Acoustic (iTA) and Longitudinal Optical $(L O)$ modes: iTALO band (maximum at about $1860 \mathrm{~cm}^{-1}$ ) [21] or band reported for cumulene CCsp $p^{1}$ vibrations (maximum at about $1980 \mathrm{~cm}^{-1}$ ) [14] is much worse.

The parameters of bands found in subtracted spectra of $n s c 1 \_1, n s c 12$, and nscl_3 samples (bottom excitation) are given in Table 2. As in Table 1, each band is characterized by maximum position, FWHM, and normalized intensity. As a reference, the intensities of bands assigned to $a$ - $C$ were chosen, because this type of band was found in subtracted spectra of all samples. The last column of Table 2 contains proposed assignment. The main common feature observed for all samples was assigned to $a$-C [22]. The maxima of this band are placed at $\sim 1525 \mathrm{~cm}^{-1}, \sim 1537 \mathrm{~cm}^{-1}$, and $\sim 1518 \mathrm{~cm}^{-1}$ for $n s c 1 \_2, n s c 1 \_3$, and $n s c 1 \_$, respectively. Corresponding FWHMs are equal to about $59 \mathrm{~cm}^{-1}, 66 \mathrm{~cm}^{-1}$, and $39 \mathrm{~cm}^{-1}$. The $a-C$ layer placed at the interface of $\mathrm{SiC}$ was already observed with cross-sectional transmission electron microscopy in the case of thermal decomposition of $4 \mathrm{H}$ $\mathrm{SiC}$ [23]. The $a$-C layer observed for all samples in present study appears probably due to $20 \%$ in-plane lattice mismatch between $4 \mathrm{H}-\mathrm{SiC}$ and graphite combined with $60 \%$ / $80 \%$ inplane expansion mismatch reported for silicon carbide and graphite at SiC/graphite interface [23].

The bands placed between $1370 \mathrm{~cm}^{-1}$ and $1400 \mathrm{~cm}^{-1}$, in particular:

(i) for $n s c 1 \_2$ maximum at $~ 1394 \mathrm{~cm}^{-1}$;

(ii) for $n s c 1 \_3$ maximum at $\sim 1397 \mathrm{~cm}^{-1}$;

(iii) for $n s c 1 \_1$ maximum at $\sim 1378 \mathrm{~cm}^{-1}$,

are assigned to type of vibration responsible $D$ band. Typical position of the $D$ band maximum is equal to about $1350 \mathrm{~cm}^{-1}$ $[12,24-26]$. In the case of structures like carbon nanotubes, the maximum position of $D$ band is expected in the range of Raman shift between $1250 \mathrm{~cm}^{-1}$ and $1450 \mathrm{~cm}^{-1}$ [27]. In carbon films, the position of $D$ band maximum was reported as equal to about $1380 \mathrm{~cm}^{-1}$ [19]. The band with maximum at about $1319 \mathrm{~cm}^{-1}$ corresponds to the data reported for cubic diamond [28]. This kind of carbon structure is formed form graphite which has $\mathrm{ABC}$ stacking order. Such a type of graphite is preferentially formed in the process of thermal decomposition of silicon carbide [9]. This kind of diamond can be formed under low pressure in the presence of nickel which plays a role of catalyst in formation of cubic diamond [28]. The activation barrier of diamond formation form graphite is slightly lower for cubic form of diamond than for hexagonal type [28]. The correlation of the maximum $1319 \mathrm{~cm}^{-1}$ with band reported for carbon nanotubes is much worse [29]. The changes of Raman spectra recorded for bottom excitation for samples nscl_2, nscl_3, and $n s c 1 \_1$ in the range below $1400 \mathrm{~cm}^{-1}$ can be summarized in the following way. Thermal treatment at $800^{\circ} \mathrm{C}$ applied to $n s c 122$ sample results in formation of structures generating $D$ band with maximum at $1394 \mathrm{~cm}^{-1}$. The maximum of the band is shifted towards higher frequencies in comparison with typical position of $D$ band equal to about $1350 \mathrm{~cm}^{-1}$. The reason for this shift is probably the interaction with nitrogen used for doping of the substrate [10]. Such kind of shift resulting from interaction with nitrogen was already reported for carbon film deposited on silicon substrate [30, 31]. Increase of the temperature in second step of thermal treatment of the samples up to $950^{\circ} \mathrm{C}$ [10] results in formation of cubic diamond-like structures observed as a weak band with maximum at $1319 \mathrm{~cm}^{-1}$ in $n s c 1 \_3$ subtracted Raman spectrum. Further increase of the annealing temperature up to $1000^{\circ} \mathrm{C}$ causes the graphitization of the sample. The trace of this graphitization is observed for $n s c 1 \_1$. $D$ band obtained for subtracted spectrum is shifted towards standard position in comparison with data recorded for $n s c 1 \_2$ and $n s c 1 \_3$ samples.

The other strong band observed in the spectrum of nsc1_2 obtained for bottom excitation has the maximum at about $1602 \mathrm{~cm}^{-1}$ and FWHM equal to about $57 \mathrm{~cm}^{-1}$. These values are almost the same as parameters describing $G$ band observed for the same sample in the case of top excitation and are typical for spectra observed in the case of nanocrystalline graphite $[13,32,33]$. The maximum of $G$ band is shifted in the case of $n s c 1 \_3$ towards higher frequencies and is placed at about $1610 \mathrm{~cm}^{-1}$. This kind of shift suggests increase of the concentration of the double $\mathrm{C}=\mathrm{C}$ bonds. The maximum of Raman band associated with vibration of double $\mathrm{C}=\mathrm{C}$ bonds is placed at about $1620 \mathrm{~cm}^{-1}$ [34]. Small band with maximum placed at about $1566 \mathrm{~cm}^{-1}$ in subtracted spectrum of $n s c 1 \_3$ is well correlated with data reported for carbon nanotubes and known as $G^{-}$band [27]. In the case of nscl_1 sample, the second important band has the maximum placed at about $1580 \mathrm{~cm}^{-1}$, which is in agreement with the position of $G$ band reported for graphite $[12,24]$. The band with maximum at $1644 \mathrm{~cm}^{-1}$ obtained for $n s c 1+1$ is assigned to $C=C$ stretching vibrations. The typical reported value $1620 \mathrm{~cm}^{-1}$ corresponding to double bond $\mathrm{C}=\mathrm{C}$ vibration can be modified by the environment. An example of such behaviour is delivered by Raman study of liquid hydrocarbons-botryococcenes. In this type of compounds, three bands, $1640 \mathrm{~cm}^{-1}, 1647 \mathrm{~cm}^{-1}$, and $1670 \mathrm{~cm}^{-1}$, were assigned to $\mathrm{C}=\mathrm{C}$ stretching vibrations [35]. In summary, with increase the temperature of second step of annealing process $G$ band moves to the typical position reported for graphite. In each sample, large content of $\mathrm{C}=\mathrm{C}$ vibration is observed. In the case of nscl_ 3 sample also, the 
TABLE 2: Summary of results obtained in the case of bottom excitation. The range of Raman shift which was taken into account spreads from $1300 \mathrm{~cm}^{-1}$ to $1880 \mathrm{~cm}^{-1}$.

\begin{tabular}{|c|c|c|c|c|c|c|c|c|c|}
\hline \multirow[b]{2}{*}{$\begin{array}{l}\text { Max. } \\
\left(\mathrm{cm}^{-1}\right)\end{array}$} & \multirow{2}{*}{$\begin{array}{c}\text { nscl_2 } \\
\text { FWHM } \\
\left(\mathrm{cm}^{-1}\right)\end{array}$} & \multirow[b]{2}{*}{$\begin{array}{l}\text { Norm. } \\
\text { Int. }\end{array}$} & \multirow[b]{2}{*}{$\begin{array}{l}\text { Max. } \\
\left(\mathrm{cm}^{-1}\right)\end{array}$} & \multicolumn{2}{|l|}{$n s c 1$-3 } & \multicolumn{3}{|c|}{$n s c 1 \_1$} & \multirow[b]{2}{*}{ Assignment } \\
\hline & & & & $\begin{array}{l}\text { FWHM } \\
\left(\mathrm{cm}^{-1}\right)\end{array}$ & $\begin{array}{l}\text { Norm. } \\
\text { Int. }\end{array}$ & $\begin{array}{l}\text { Max. } \\
\left(\mathrm{cm}^{-1}\right)\end{array}$ & $\begin{array}{l}\text { FWHM } \\
\left(\mathrm{cm}^{-1}\right)\end{array}$ & $\begin{array}{l}\text { Norm. } \\
\text { Int. }\end{array}$ & \\
\hline & & & 1319.2 & 32.1 & 0.22 & & & & $\begin{array}{l}\text { Cubic diamond-like } \\
\text { structures }\end{array}$ \\
\hline 1393.5 & 96.6 & 0.23 & 1397.0 & 88.0 & 0.20 & 1378.2 & 104.0 & 0.19 & $D$-band \\
\hline \multirow[t]{3}{*}{1525.3} & 58.8 & 1.00 & 1537.1 & 66.4 & 1.00 & 1517.5 & 39.2 & 1.00 & $a-\mathrm{C}$ \\
\hline & & & 1566.2 & 9.3 & 0.20 & & & & $\begin{array}{l}G \text {-band, carbon } \\
\text { nanotubes }\end{array}$ \\
\hline & & & & & & 1580.0 & 33.0 & 0.79 & $G$-band, graphite \\
\hline \multirow[t]{3}{*}{1601.7} & 56.7 & 0.60 & & & & & & & $\begin{array}{l}\text { G-band, } \\
\text { nanocrystalline } \\
\text { graphite }\end{array}$ \\
\hline & & & 1610.3 & 47.7 & 1.17 & & & & $\begin{array}{l}\text { Combination of } \\
G \text {-band and } D^{\prime} \text {-band } \\
(\mathrm{C}=\mathrm{C} \text { vibrational } \\
\text { modes })\end{array}$ \\
\hline & & & & & & 1644.4 & 33.1 & 0.13 & $\begin{array}{l}D^{\prime} \text {-band }(\mathrm{C}=\mathrm{C} \\
\text { vibrational modes })\end{array}$ \\
\hline \multirow[t]{2}{*}{1706.6} & 62.2 & 0.19 & 1693.8 & 73.8 & 0.38 & 1709.8 & 25.5 & 0.45 & $\begin{array}{l}\text { Benzene-related } \\
\text { vibrations or } 2 o T O \\
\text { mode }\end{array}$ \\
\hline & & & 1795.2 & 42.4 & 0.14 & 1792.2 & 159.2 & 0.17 & iTALO or $20 T O$ mode \\
\hline
\end{tabular}

traces of carbon nanotubes were observed in Raman spectra excited through $4-\mathrm{SiC}$ substrate.

The bands placed between about $1700 \mathrm{~cm}^{-1}$ and $1900 \mathrm{~cm}^{-1}$ can be classified as one group. In the case of the sample $n s c 1 \_2$, only one band of this type can be recognized in this range of Raman shift. It is placed around $1707 \mathrm{~cm}^{-1}$. For $n s c 1_{-} 3$ and $n s c 1 \_1$, two bands appear in Raman spectra in the range $1700 \mathrm{~cm}^{-1} / 1900 \mathrm{~cm}^{-1}$. The maxima positions of the bands are placed at $1694 \mathrm{~cm}^{-1}$, and $1795 \mathrm{~cm}^{-1}$ for $n s c 1 \_3$. For $n s c 1 \_1$ the corresponding values are equal to $1710 \mathrm{~cm}^{-1}$ and $1792 \mathrm{~cm}^{-1}$. The bands placed near $1700 \mathrm{~cm}^{-1}$ have the best correlation with the $M$ band assigned to the infrared active 2oTO mode [18]. This mode has two components $M^{-}$and $M^{+}$. The $M$ band is of great interest in the case of structural investigation of carbon nanotubes [29]. The $M^{-}$band is dispersive, whereas the position of $M^{+}$maximum does not change with excitation wavelength [17]. The maxima positions of $M$ band components depend on the type of carbon structure. For example, in the case single wall carbon nanotubes (SWCNTs), the maxima of $M^{-}$and $M^{+}$bands are placed in ranges $1732 \mathrm{~cm}^{-1} / 1744 \mathrm{~cm}^{-1}$ and $1755 \mathrm{~cm}^{-1} / 1766 \mathrm{~cm}^{-1}$, respectively [18]. The maxima positions depend on the tube diameter, and they moved towards higher frequencies with the increase of this diameter. For "planar" forms of carbon, $M^{-}$and $M^{+}$are shifted above $1750 \mathrm{~cm}^{-1}$ [17]. For example, in the case of highly ordered pyrolytic graphite (HOPG), the maxima are placed at $1754 \mathrm{~cm}^{-1}$ and $1775 \mathrm{~cm}^{-1}$ [18]. There are two other possibilities of assignment. The bands $1707 \mathrm{~cm}^{-1}, 1694 \mathrm{~cm}^{-1}$, and $1710 \mathrm{~cm}^{-1}$ can be correlated with benzene-related vibrations. The corresponding band assigned to benzene-related vibrations in carbon films is placed around $1740 \mathrm{~cm}^{-1}$ [19]. The other possible assignment is concerned with bands maxima at $1795 \mathrm{~cm}^{-1}$ and $1792 \mathrm{~cm}^{-1}$. These values are not far from the maximum of vibrations assigned to iTALO mode. The reported maximum of $i T A L O$ band is placed at about $1860 \mathrm{~cm}^{-1}$ [21]. The correlation with band reported for cumulene chains placed around $1980 \mathrm{~cm}^{-1}$ is much worse [14]. To sum up, the bands $1707 \mathrm{~cm}^{-1}, 1694 \mathrm{~cm}^{-1}$, and $1710 \mathrm{~cm}^{-1}$ can be assigned to $20 T O$ modes or benzenerelated vibrations and bands $1795 \mathrm{~cm}^{-1}$ and $1792 \mathrm{~cm}^{-1}$ should be correlated with 20 TO or iTALO modes.

Table 3 summarizes the features of Raman spectra measured for $n s c 1 \_3$ and $n s c 1 \_1$ with top excitation in the range corresponding to $2 \mathrm{D}$ band. Each component is characterized by maximum position, FWHM, and normalized intensity. The intensity of the most intense Gaussian profile in the spectrum of each sample, in particular, $2704.4 \mathrm{~cm}^{-1}$ for $n s c 1 \_3$ and $2700.4 \mathrm{~cm}^{-1}$ for $n s c 1 \_1$, was normalized to unity. The last column of the table contains proposed assignment. $2 \mathrm{D}$ band appears in double resonance mechanism [36] and is susceptible to the carbon structure. For example, Raman spectrum of so-called two-dimensional graphite (without stacking order) has $2 D$ band which can be reproduced with single Lorentzian function centred at $2707 \mathrm{~cm}^{-1}$ [37]. This type of structure is called turbostatic graphite. To describe $2 D$ band of three-dimensional graphite with mathematical model, two Lorentzian functions are necessary [37]. They have maxima at $2687 \mathrm{~cm}^{-1}$ and $2727 \mathrm{~cm}^{-1}$. The shape of $2 D$ band is very sensitive to the number of layers in graphite sample especially for so-called "few-graphene layers" [22]. In 
TABLE 3: Summary of results obtained for $2 D$ band. Spectra were measured for top excitation.

\begin{tabular}{|c|c|c|c|c|c|c|}
\hline & $n s c 1 \_3$ & & & $n s c 1 \_1$ & & \\
\hline $\begin{array}{l}\text { Max. } \\
\left(\mathrm{cm}^{-1}\right)\end{array}$ & $\begin{array}{c}\text { FWHM } \\
\left(\mathrm{cm}^{-1}\right)\end{array}$ & $\begin{array}{c}\text { Norm. } \\
\text { Int. }\end{array}$ & $\begin{array}{l}\text { Max. } \\
\left(\mathrm{cm}^{-1}\right)\end{array}$ & $\begin{array}{c}\text { FWHM } \\
\left(\mathrm{cm}^{-1}\right)\end{array}$ & $\begin{array}{l}\text { Norm. } \\
\text { Int. }\end{array}$ & Assignment \\
\hline 2659.6 & 67.0 & 0.31 & 2641.8 & 52.9 & 0.16 & $\begin{array}{l}\text { "Narrow" component overtone } \\
\text { accompanied by interaction with "broad" } \\
\text { component }\end{array}$ \\
\hline 2704.4 & 56.2 & 1.00 & 2700.4 & 61.6 & 1.00 & "Narrow" component overtone \\
\hline 2724.6 & 61.9 & 0.86 & 2719.9 & 48.9 & 0.89 & "Broad" component overtone \\
\hline 2766.5 & 51.5 & 0.18 & 2752.2 & 60.6 & 0.39 & $\begin{array}{l}\text { "Broad" component overtone } \\
\text { accompanied by interaction with } \\
\text { "narrow" component }\end{array}$ \\
\hline
\end{tabular}

the case of graphene, $2 D$ band can be modeled with single Lorentzian function [22]. The band splits into multiprofile structure due to splitting of electronic band structure and interaction between "graphene" layers if the number of layers increases [38]. This splitting causes four processes contributing to $2 D$ band. Two of them introduce components with relatively strong intensity, while two others give a rise to weaker components. The most spectacular changes of $2 D$ band are observed in the case of numbers of layers below ten [39]. "Graphene bilayer" requires four Lorentzian components for proper mathematical representation of $2 D$ band [40]. In the case of "graphene three-layer", it is necessary to use even six Lorentzian functions to reproduce properly the band shape [16]. The analysis of $G$ band observed for samples nscl_1 and nscl_3 suggests that carbon few-layer can be divided into two sublayers: one with dominant $A B C$ stacking order and the other with dominant $\mathrm{ABA}$ stacking order. Graphite with ABA stacking order (Bernal type) shows metallic-like behaviour [41]. The rhombohedral graphite shows the properties of narrow-band semiconductor [41] which has the band-gap equal to about $6 \mathrm{meV}$ around $K$ point [41]. The band-gap in $n$-"graphene"-layer depends on the number of layers $n$ and the stacking order. For example, calculated band-gap from first principle for rhombohedral graphite changes from $18 \mathrm{meV}$ to $4.8 \mathrm{meV}$ if sequence and number of layers change from $\mathrm{ABC}$ to $\mathrm{ABCA}$ [42]. The fourlayer with stacking order $\mathrm{ABAC}$ should have two band-gaps: "quasidirect" equal to $8.8 \mathrm{meV}$ and secondary (around $\mathrm{K}$ point) equal to $11.5 \mathrm{meV}$ [42]. Reported values of band-gap, $4.8 \mathrm{meV} / 18 \mathrm{meV}$, correspond to the range $39 \mathrm{~cm}^{-1} / 145 \mathrm{~cm}^{-1}$. This range of band gap corresponds to the energy of two vibrational modes in carbon structures: $E_{2 \mathrm{~g}}$ and $B_{2 \mathrm{~g}}[43] . E_{2 \mathrm{~g}}$ vibrational mode contributes to Raman spectrum of HOPG as weak line centred around $42 \mathrm{~cm}^{-1}$ [43-45]. In the case of carbon nanotubes, the reported frequency of this mode is equal to $49 \mathrm{~cm}^{-1}$ or $58 \mathrm{~cm}^{-1}$ depending on the tube diameter [44]. The $B_{2 \mathrm{~g}}$ mode was observed in Raman spectra of HOPG as weak line with maximum at $127 \mathrm{~cm}^{-1}$ [43-45].

We will adopt the concept of interacting layers to explain the origin of four Gaussian components of $2 D$ band. Instead of "graphene" layers, we have two graphite sublayers with $\mathrm{ABA}$ - and $\mathrm{ABC}$-dominant stacking orders. One has to take into account that scattering accompanied by interaction between carbon sub-layers with different stacking order requires in the energy balance the quantum related to small band-gap in part of carbon layer with dominant $\mathrm{ABC}$ stacking order. Let us now come back to the measured Raman spectra. The components of $2 D$ band recorded for $n s c 111$ and centred around $2700 \mathrm{~cm}^{-1}$ and $2720 \mathrm{~cm}^{-1}$ can be assigned to overtones "narrow" and "broad" parts of $D$ band, respectively. Similar assignment can be carried out for strong components of $2 D$ band (maxima $2704 \mathrm{~cm}^{-1}$ and $2725 \mathrm{~cm}^{-1}$ ) observed for $n s c 1$. 3 . Weak components with frequencies $2660 \mathrm{~cm}^{-1}$ for $n s c 1 \_3$ and $2642 \mathrm{~cm}^{-1}$ for $n s c 1 \_1$ can be assigned to overtone of "narrow" component of $D$ band shifted due to energy exchange with "broad" component of the same band. Symmetrically, the components centred around $2767 \mathrm{~cm}^{-1}$ for $n s c l \_3$ and $2752 \mathrm{~cm}^{-1}$ for $n s c l l \mathrm{can}$ be treated as overtone of "broad" component of $D$ band arising in scattering accompanied with energy exchange with "narrow" component of the same band. "Weak" components in Raman spectrum of $2 D$ band observed for $n s c 1 \_1$ are shifted towards smaller values of Raman shift in comparison with spectrum obtained for $n s c 1$. 3 . This shift is equal to about $15 \mathrm{~cm}^{-1} / 18 \mathrm{~cm}^{-1}$ and is due to changes in stacking caused by higher annealing temperature. An example of electronic excitation and vibrational modes joined action was reported in the case of intramolecular excited state proton transfer reaction [46]. The tautomerization mechanism of [2,2-bipyridine]-3,3' -diol was explained in [46] in terms of wavepacket evolution triggered by electronic excitation.

\section{Summary}

Let us state at the beginning that application of Gaussian profiles significantly improved the quality of the fitting procedure in comparison with former approach based on Lorentzian functions [10]. This is probably due to complicated character of the spectra. Gaussian function is focused on the information from the vicinity of maximum of the band, whereas in case of Lorentzian profile, the tails far from the maximum play much more important role than for Gaussian function.

The part of carbon layer place at the $\mathrm{SiC} / \mathrm{C}$ interface has complex structure. The existence of such amorphous component probably cannot be avoided because of lattice mismatch between silicon carbide and graphite [47] and differences 
between in-plane thermal expansion of silicon carbide and graphite [23]. The complicated character of Raman spectra suggests that the achieving low-resistance ohmic contacts is not only dependent on graphitization process understood as decrease of the concentration of defects in graphite lattice. It also includes more subtle processes like changes in stacking order or creation of structures like carbon nanotubes. It is especially important in the vicinity of $\mathrm{SiC} / \mathrm{C}$ interface. The nanotube-like structure should have much better electric properties [48] than amorphous carbon placed on the $\mathrm{SiC} / \mathrm{C}$ interface [49].

\section{Acknowledgment}

The research was partially supported by the European Union within European Regional Development Fund, through grant Innovative Economy (POIG.01.03.01-00-159/08 "InTechFun").

\section{References}

[1] J. A. Cooper and A. Agarwal, "SiC power-switching devices-the second electronics revolution?" Proceedings of the IEEE, vol. 90, no. 6, pp. 956-968, 2002.

[2] R. C. Clarke and J. W. Palmour, "SiC microwave power technologies," Proceedings of the IEEE, vol. 90, no. 6, pp. 987-992, 2002.

[3] H. Matsunami, "Current SiC technology for power electronic devices beyond Si," Microelectronic Engineering, vol. 83, no. 1, pp. 2-4, 2006.

[4] J. Crofton, P. G. McMullin, J. R. Williams, and M. J. Bozack, "High-temperature ohmic contact to n-type $6 \mathrm{H}$-SiC using nickel," Journal of Applied Physics, vol. 77, no. 3, pp. 1317-1319, 1995.

[5] M. G. Rastegaeva, A. N. Andreev, A. A. Petrov, A. I. Babanin, M. A. Yagovkina, and I. P. Nikitina, "The influence of temperature treatment on the formation of Ni-based Schottky diodes and ohmic contacts to n-6H-SiC," Materials Science and Engineering B, vol. 46, no. 1-3, pp. 254-258, 1997.

[6] W. Lu, W. C. Mitchel, C. A. Thornton, G. R. Landis, and W. Eugene Collins, "Carbon structural transitions and ohmic contacts on $4 \mathrm{H}-\mathrm{SiC}$," Journal of Electronic Materials, vol. 32, no. 5, pp. 426-431, 2003.

[7] W. Lu, W. C. Mitchel, G. R. Landis, T. R. Crenshaw, and W. E. Collins, "Electrical contact behavior of Ni/C60/4H-SiC structures," Journal Vacuum Science \& Technology A, vol. 21, no. 4, pp. 1510-1514, 2003.

[8] A. Kuchuk, V. Kladko, M. Guziewicz et al., "Fabrication and characterization of nickel silicide ohmic contacts to n-type $4 \mathrm{H}$ silicon carbide," Journal of Physics, vol. 100, no. 4, Article ID 042003, 2008.

[9] W. Norimatsu and M. Kusunoki, "Selective formation of ABCstacked graphene layers on SiC(0001)," Physical Review B, vol. 81, no. 16, Article ID 161410, 2010.

[10] P. Borowicz, A. Kuchuk, Z. Adamus et al., "Visible and deepultraviolet Raman spectroscopy as a tool for investigation of structural changes and redistribution of carbon in Ni-based ohmic contacts on silicon carbide," ISRN Nanomaterials, vol. 2012, Article ID 852405, 11 pages, 2012.

[11] P. Borowicz, T. Gutt, T. Małachowski, and M. Latek, "Carbonic inclusions on $\mathrm{SiC} / \mathrm{SiO}_{2}$ interface investigated with Raman
Scattering," Diamond and Related Materials, vol. 20, no. 5-6, pp. 665-674, 2011.

[12] A. C. Ferrari and J. Robertson, "Interpretation of Raman spectra of disordered and amorphous carbon," Physical Review B, vol. 61, no. 20, pp. 14095-14107, 2000.

[13] A. C. Ferrari and J. Robertson, "Raman spectroscopy of amorphous, nanostructured, diamond-like carbon, and nanodiamond," Philosophical Transactions of the Royal Society A, vol. 362, no. 1824, pp. 2477-2512, 2004.

[14] L. Ravagnan, F. Siviero, C. Lenardi et al., "Cluster-beam deposition and in situ characterization of carbyne-rich carbon films," Physical Review Letters, vol. 89, no. 28, pp. 285506/1-285506/4, 2002.

[15] C. H. Lui, Z. Li, Z. Chen, P. V. Klimov, L. E. Brus, and T. F. Heinz, "Imaging stacking order in few-layer graphene," Nano Letters, vol. 11, no. 1, pp. 164-169, 2011.

[16] C. Cong, T. Yu, K. Sato et al., "Raman characterization of ABAand ABC-stacked trilayer graphene," ACS Nano, vol. 5, no. 11, pp. 8760-8768, 2011.

[17] C. Cong, T. Yu, R. Saito, G. F. Dresselhaus, and M. S. Dresselhaus, "Second-order overtone and combination raman modes of graphene layers in the range of 1690-2150 cm-1," ACS Nano, vol. 5, no. 3, pp. 1600-1605, 2011.

[18] V. W. Brar, G. G. Samsonidze, M. S. Dresselhaus et al., "Secondorder harmonic and combination modes in graphite, singlewall carbon nanotube bundles, and isolated single-wall carbon nanotubes," Physical Review B, vol. 66, no. 15, Article ID 155418, pp. 1554181-15541810, 2002.

[19] N. Radić, B. Pivac, F. Meinardi, and T. Koch, "Raman study of carbon clusters in W-C thin films," Materials Science and Engineering A, vol. 396, no. 1-2, pp. 290-295, 2005.

[20] Z. Y. Chen, J. P. Zhao, T. Yano, T. Ooie, M. Yoneda, and J. Sakakibara, "Observation of sp3 bonding in tetrahedral amorphous carbon using visible Raman spectroscopy," Journal of Applied Physics, vol. 88, no. 5, pp. 2305-2308, 2000.

[21] R. Rao, R. Podila, R. Tsuchikawa et al., "Effects of layer stacking on the combination raman modes in graphene," ACS Nano, vol. 5, no. 3, pp. 1594-1599, 2011.

[22] A. C. Ferrari, "Raman spectroscopy of graphene and graphite: disorder, electron-phonon coupling, doping and nonadiabatic effects," Solid State Communications, vol. 143, no. 1-2, pp. 47-57, 2007.

[23] R. Colby, M. L. Bolen, M. A. Capano, and E. A. Stach, "Amorphous interface layer in thin graphite films grown on the carbon face of SiC," Applied Physics Letters, vol. 99, Article ID 101904, 2011.

[24] F. Tuinstra and J. L. Koenig, "Raman spectrum of graphite," Journal of Chemical Physics, vol. 53, no. 3, pp. 1126-1130, 1970.

[25] R. J. Nemanich and S. A. Solin, "First- and second-order Raman scattering from finite-size crystals of graphite," Physical Review B, vol. 20, no. 2, pp. 392-401, 1979.

[26] J. Maultzsch, S. Reich, and C. Thomsen, "Double-resonant Raman scattering in graphite: interference effects, selection rules, and phonon dispersion," Physical Review B, vol. 70, no. 15, Article ID 155403, pp. 155403-9, 2004.

[27] M. S. Dresselhaus, G. Dresselhaus, A. Jorio, A. G. S. Filho, and R. Saito, "Raman spectroscopy on isolated single wall carbon nanotubes," Carbon, vol. 40, no. 12, pp. 2043-2061, 2002.

[28] M. Nishitani-Gamo, I. Sakaguchi, K. P. Loh, H. Kanda, and T. Ando, "Confocal Raman spectroscopic observation of hexagonal diamond formation from dissolved carbon in nickel under 
chemical vapor deposition conditions," Applied Physics Letters, vol. 73, no. 6, pp. 765-767, 1998.

[29] A. M. Rao, E. Richter, S. Bandow et al., "Diameter-selective Raman scattering from vibrational modes in carbon nanotubes," Science, vol. 275, no. 5297, pp. 187-190, 1997.

[30] J. R. Shi, X. Shi, Z. Sun, E. Liu, B. K. Tay, and S. P. Lau, "Ultraviolet and visible Raman studies of nitrogenated tetrahedral amorphous carbon films," Thin Solid Films, vol. 366, no. 1-2, pp. 169$174,2000$.

[31] H. Riascos, G. Zambrano, E. Camps, and P. Prieto, "Influence of nitrogen gas pressure on plume-plasma and chemical bonding of carbon nitride films synthesized by pulsed laser deposition," Revista Mexicana de Fisica, vol. 53, no. 7, pp. 274-278, 2007.

[32] W. Lu, W. C. Mitchel, G. R. Landis, T. R. Crenshaw, and W. E. Collins, "Catalytic graphitization and Ohmic contact formation on 4H-SiC," Journal of Applied Physics, vol. 93, no. 9, pp. 5397$5403,2003$.

[33] V. Y. Osipov, A. V. Baranov, V. A. Ermakov et al., "Raman characterization and UV optical absorption studies of surface plasmon resonance in multishell nanographite," Diamond and Related Materials, vol. 20, no. 2, pp. 205-209, 2011.

[34] C. Fantini, M. A. Pimenta, and M. S. Strano, “Two-phonon combination Raman modes in covalently functionalized singlewall carbon nanotubes," Journal of Physical Chemistry C, vol. 112, no. 34, pp. 13150-13155, 2008.

[35] T. L. Weiss, H. J. Chun, S. Okada et al., "Raman spectroscopy analysis of botryococcene hydrocarbons from the green microalga Botryococcus braunii," Journal of Biological Chemistry, vol. 285, no. 42, pp. 32458-32466, 2010.

[36] P. H. Tan, C. Y. Hu, J. Dong, and W. C. Shen, "Double resonance Raman scattering of second-order Raman modes from an individual graphite whisker," Physica E, vol. 37, no. 1-2, pp. 9396, 2007.

[37] M. A. Pimenta, G. Dresselhaus, M. S. Dresselhaus, L. G. Cançado, A. Jorio, and R. Saito, "Studying disorder in graphitebased systems by Raman spectroscopy," Physical Chemistry Chemical Physics, vol. 9, no. 11, pp. 1276-1291, 2007.

[38] R. Narula and S. Reich, "Double resonant Raman spectra in graphene and graphite: a two-dimensional explanation of the Raman amplitude," Physical Review B, vol. 78, no. 16, Article ID 165422, 2008.

[39] D. Yoon, H. Moon, H. Cheong, J. S. Choi, J. A. Choi, and B. H. Park, "Variations in the Raman spectrum as a function of the number of graphene layers," Journal of the Korean Physical Society, vol. 55, no. 3, pp. 1299-1303, 2009.

[40] A. C. Ferrari, J. C. Meyer, V. Scardaci et al., "Raman spectrum of graphene and graphene layers," Physical Review Letters, vol. 97, no. 18, Article ID 187401, 2006.

[41] P. Xu, Y. Yang, I. D. Qi et al., "A pathway between Bernal and rhombohedral stacked graphene layers with scanning tunnelling microscopy," Applied Physics Letters, vol. 100, Article ID 201601, 2012.

[42] S. Latil and L. Henrard, "Charge carriers in few-layer graphene films," Physical Review Letters, vol. 97, no. 3, Article ID 036803 , 2006.

[43] Y. Wang, D. C. Alsmeyer, and R. L. McCreery, "Raman spectroscopy of carbon materials: structural basis of observed spectra," Chemistry of Materials, vol. 2, no. 5, pp. 557-563, 1990.

[44] P. C. Eklund, J. M. Holden, and R. A. Jishi, "Vibrational modes of carbon nanotubes; Spectroscopy and theory," Carbon, vol. 33, no. 7, pp. 959-972, 1995.
[45] R. Kostić, M. Mirić, T. Radić, M. Radović, R. Gajić, and Z. V. Popović, "Optical characterization of graphene and highly oriented pyrolytic graphite," Acta Physica Polonica A, vol. 116, no. 4, pp. 718-721, 2009.

[46] K. Stock, C. Schriever, S. Lochbrunner, and E. Riedle, "Reaction path dependent coherent wavepacket dynamics in excited state intramolecular double proton transfer," Chemical Physics, vol. 349, no. 1-3, pp. 197-203, 2008.

[47] L. B. Biedermann, M. L. Bolen, M. A. Capano, D. Zemlyanov, and R. G. Reifenberger, "Insights into few-layer epitaxial gra-

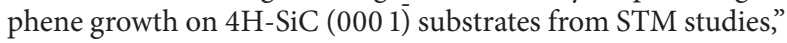
Physical Review B, vol. 79, no. 12, Article ID 125411, 2009.

[48] P. R. Bandaru, "Electrical properties and applications of carbon nanotube structures," Journal of Nanoscience and Nanotechnology, vol. 7, no. 4-5, pp. 1239-1267, 2007.

[49] L. Kumari and S. V. Subramanyam, "Structural and electrical properties of amorphous carbon-sulfur composite films," Bulletin of Materials Science, vol. 27, no. 3, pp. 289-294, 2004. 

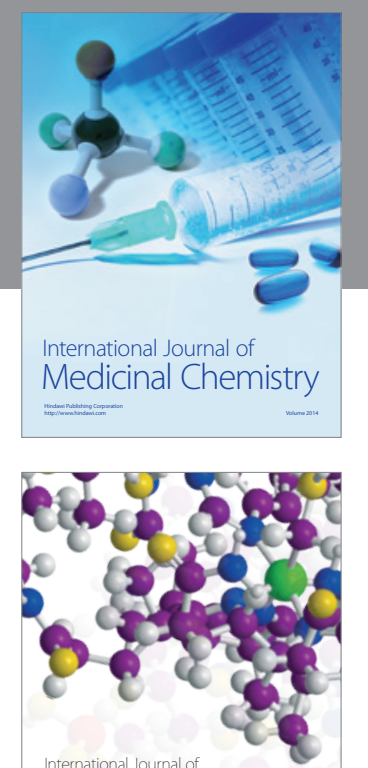

\section{Carbohydrate} Chemistry

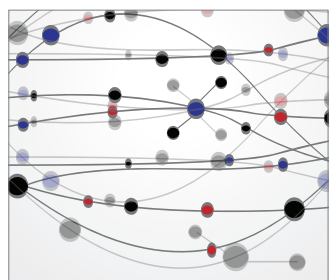

The Scientific World Journal
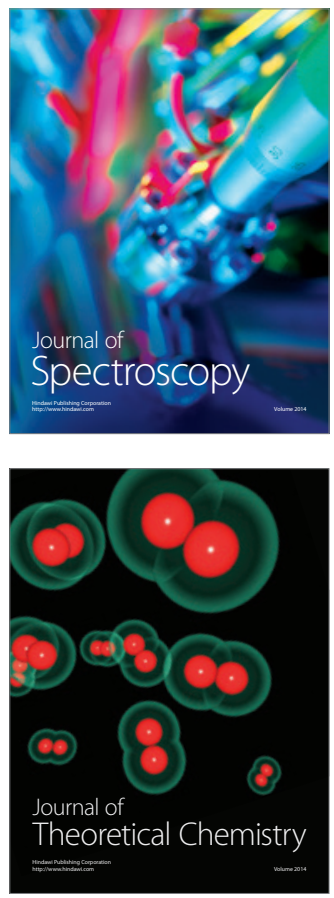
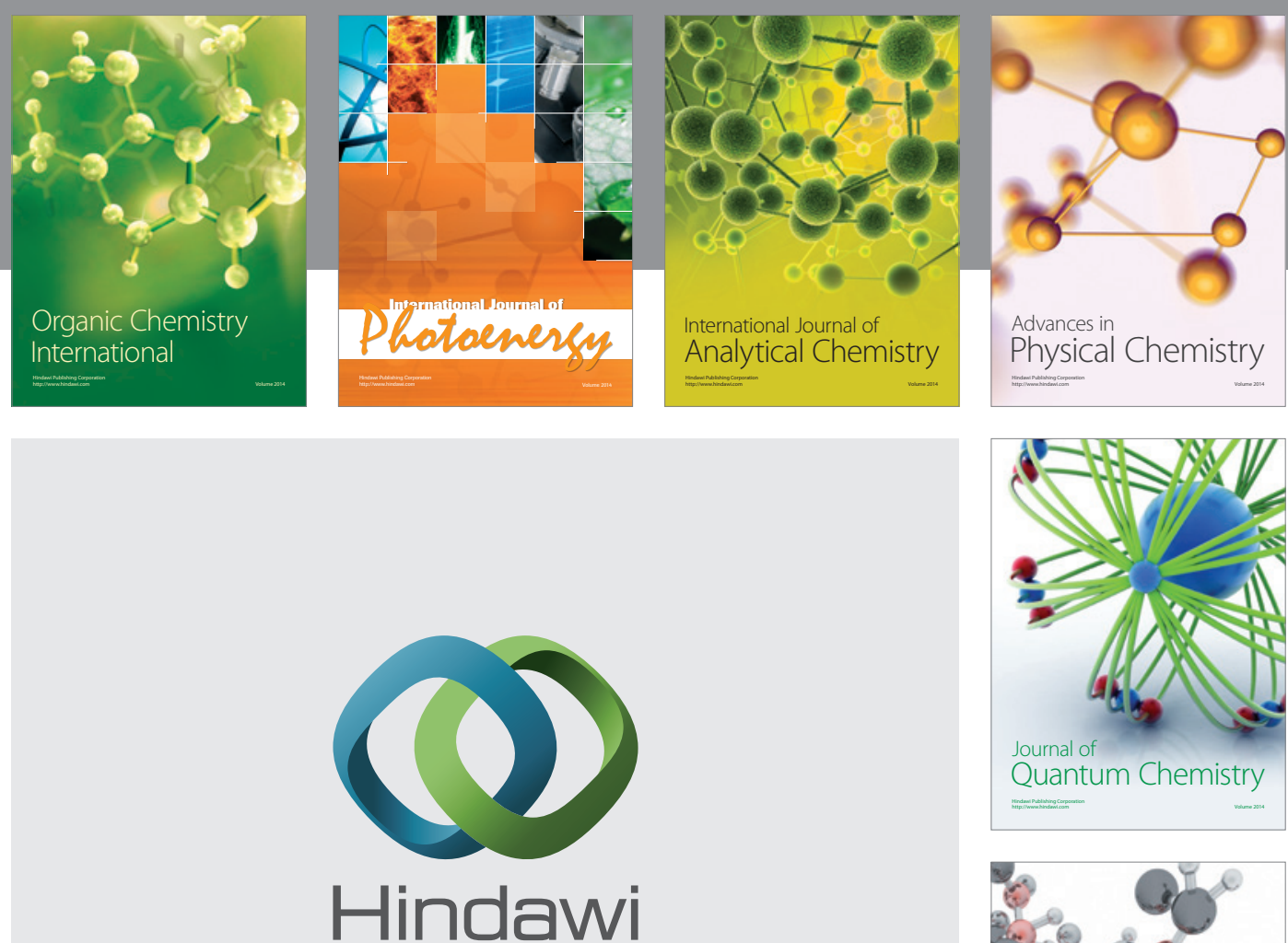

Submit your manuscripts at

http://www.hindawi.com

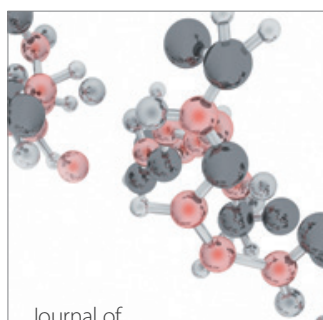

Analytical Methods

in Chemistry

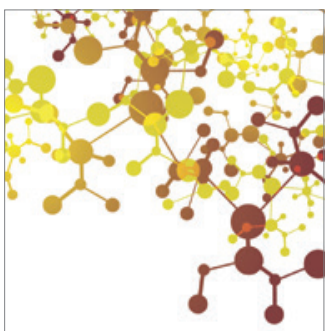

Journal of

Applied Chemistry

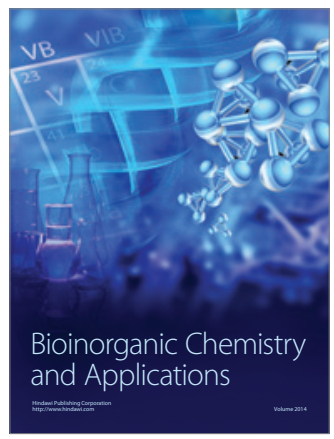

Inorganic Chemistry
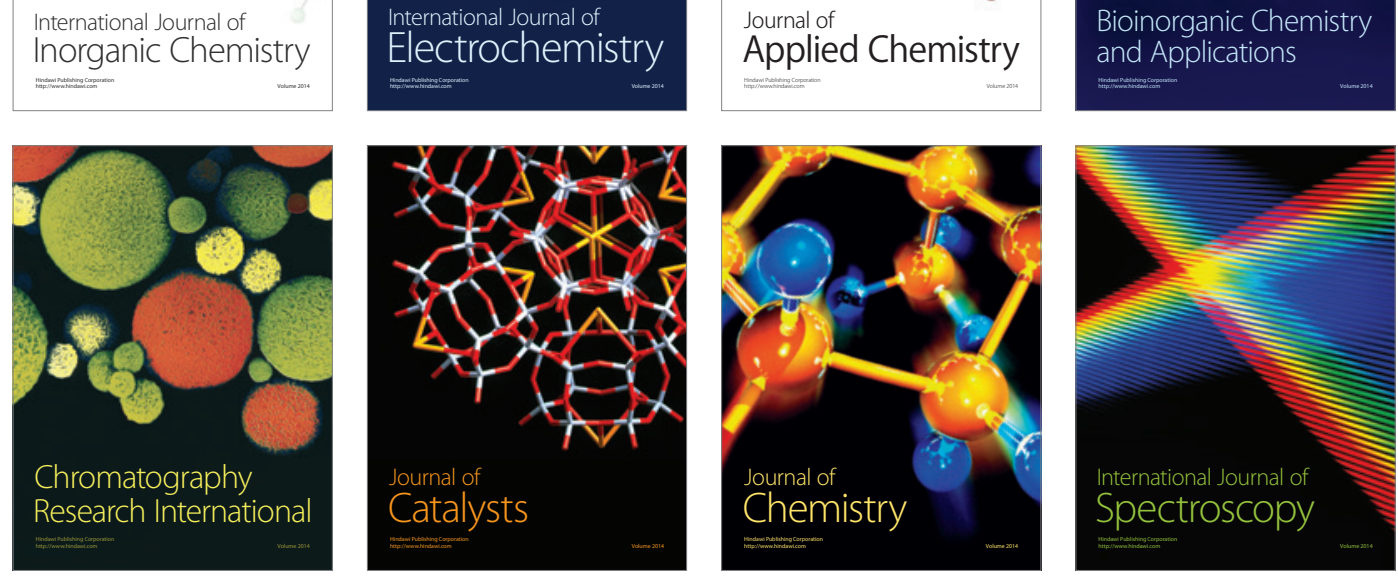